\title{
VOCACIÓN Y ESTADOS DE PERFECCIÓN EN SAN JUAN DE ÁVILA
}

Pedro Cayón Cagigas ${ }^{1}$

DOI: https://doi.org/10.52039/seminarios.v57i201-202.336

\section{INTRODUCCIÓN}

En el presente artículo se intenta abordar uno de los temas fundamentales de la doctrina avilista, como es la vocación cristiana y, junto a ella, el talante con el que debe ser vivida en los diferentes estados en los que desenvuelve, pues la vocación es siempre una pero los caminos que recorren los hombres para desarrollarla son diversos. Si en algo destaca el Maestro Ávila es en que constituye un auténtico maestro de la vocación cristiana: esta preocupación se puede verificar simplemente ojeando sus numerosas cartas de dirección espiritual, donde precisamente no encontraremos una teología vocacional explícita, pero sí aparecen unos jalones teológicos circunscritos a lo vocacional que siguen hoy vigentes, como son el seguimiento de Cristo y la llamada a la santidad.

Se trata en este estudio de la vocación cristiana concretada en todos sus estados de vida, incluido el laical. Esta especificación se debe a que a lo largo de la historia el concepto de vocación ha sido acaparado teológicamente por el estado presbiteral y por la elección de vida a la luz de los consejos evangélicos ${ }^{2}$. Resumiendo en su raíz este equivocado concepto, ya dice San Juan de Ávila: «Porque no andéis todos por un camino; que ni todos han de ser casados, ni todos clérigos, ni todos frailes, ni todas monjas» ${ }^{3}$. Aun así, aquel erróneo planteamiento se ha plasmado también en el estudio de los textos avilistas, y así lo denuncia Esquerda Bifet cuando dice que «San Juan de Ávila ha sido más estudiado como Maestro de vida espiritual en los estados de vida sacerdotal y consagrada [...] Pero leyendo con atención sus escritos espirituales, nos encontramos con un Maestro de la vida cristiana en todas sus vocaciones y estados de vida» ${ }^{4}$.

Por fortuna, con el tiempo se ha producido una nueva situación a nivel teológico, que se refleja en el mismo Magisterio de la Iglesia actual. El Vaticano II ha

1. Sacerdote de la Diócesis de Santander (España). Doctor en Teología Moral por la Academia Alfonsiana de Roma. Profesor del Seminario Diocesano de Monte Corbán de Santander.

2. Cf. Concilio Vaticano II, Decr. Presbiterorum ordinis, 11.

3. San JuAn de Ávila, Obras Completas, L. Sala Balust - F. Martín Hernández, eds., Nueva edición crítica, III, Madrid 2002, Sermón 76, parf. 21 (Utilizo la última edición crítica de los escritos del Maestro ya citada. En adelante reflejaré exclusivamente el escrito específico con su numeración correspondiente).

4. J. EsqueRDA BIFET, Introducción a la doctrina de San Juan de Ávila, Madrid 2000, 440-441. 


\section{Pedro Cayón Cagigas}

suprimido definitivamente esa identificación entre «vocación» y «vocación sacerdotal y religiosa». Son muchos los pasajes del Concilio que presentan un concepto de vocación que es para todos: «Cristo murió por todos y la vocación última del hombre es realmente una sola, es decir, la vocación divina» ${ }^{5}$. La vocación se presenta desde una perspectiva de llamada-respuesta a la que están sujetos todos los hijos de Dios. La reciente Exhortación Apostólica Verbum Domini de Benedicto XVI, reafirma también el carácter dialogal de toda la revelación cristiana; de este modo «la existencia del hombre se convierte en un diálogo con Dios que habla y escucha, que llama y mueve nuestra vida» ${ }^{6}$. Por tanto, la vocación no debe ser identificada de forma exclusiva con algunas elecciones, sino que es una dimensión fundamental de la antropología cristiana y comprende la multiplicidad de los dones que se compaginan en unidad dentro de la Iglesia.

Desde el inicio al fin de la Sagrada Escritura se concentran abundantes pasajes sobre la noción de vocación o llamada para describir la interacción de Dios con la humanidad ${ }^{7}$. Dentro de un nivel pastoral, el Vaticano II asume a la comunidad misma como sujeto en estado de vocación, responsable de la promoción, del discernimiento y del cuidado de toda vocación. Por ejemplo, la Constitución dogmática Lumen gentium enseña que todos los hombres «son llamados a la católica unidad del Pueblo de Dios, que prefigura y promueve la paz universal y a la cual en modos diversos pertenecen y son ordenados, sean los fieles católicos, sean otros creyentes en Cristo, sean en general todos los hombres llamados a la salvación de la gracia de Cristo» ${ }^{8}$. Y la Gaudium et spes enseña que «la vida social no es para el hombre algo accidental, el hombre desarrolla todas sus cualidades y puede responder a su vocación, mediante el trato con los otros, la ayuda mutua y el diálogo con los hermanos» ${ }^{9}$.

En esta exposición trataremos concretamente los diferentes estados de perfección cristianos. Este concepto lo utilizo simplemente en el sentido de que todo cristiano, en su estado concreto, está llamado a la perfección o santidad; y esto a la luz del pensamiento del Maestro Ávila, sin entrar de lleno en la profundidad histórico-teológica que entraña el tema. Simplemente describiremos todos los estados de vida cristianos con los respectivos medios particulares que proporciona San Juan de Ávila para facilitar su óptimo desarrollo en prosecución hacia la santidad. Abundaremos exclusivamente en la perspectiva ascético-moral, que es uno de los caminos tradicionales propuestos por la Iglesia para el desarrollo de la vocación y su fin último de la perfección, dado que su presencia en el Maestro Ávila es indiscutible. En este sentido, la dimensión de este estudio

5. Concilio Vaticano II, Const. past. Gaudium et spes, 22.

6. Benedicto XVI, Exhort. ap., Verbum Domini, 24.

7. Cf. L. J. O'ConNeLL., «Vocazione», en M. DowneY, dir., Nuovo Dizionario di Spiritualità, Città del Vaticano 2003, 1024.

8. Concilio Vaticano II, Const. dogm. Lumen gentium, 13.

9. Concilio Vaticano II, Const. past. Gaudium et spes, 25 
se centra en la cooperación humana en la tarea de la perfección a la que el hombre es llamado por Dios y al aspecto del esfuerzo que reviste esa cooperación. En San Juan de Ávila, la ascesis, como praxis moral, consiste en el desarraigo de los vicios e implantar las virtudes por medio de un desprendimiento o dejadez de las cosas del mundo que son causa de tropiezo.

Según nuestros místicos, quien aspire a más, únase a Dios y saciará su hambre y sed insaciable de perfección. El hombre es mayor que todos y cada uno de los bienes terrenos e incluso mayor que el mundo entero, y no encuentra descanso en esos bienes ni en la posesión del mundo. Cuando se entregue a Dios en plenitud, deje de protegerse frente a él, encontrará la alegría y felicidad. El hombre es una copia finita de Dios infinito, está hecho para Dios y no encontrará descanso, alegría y felicidad plenas sino en Él ${ }^{10}$.

Esta temática, siendo esencial dentro de la doctrina del «maestro de la mística española», en palabras de Menéndez Pelayo, ha quedado desgraciadamente olvidada en las diferentes publicaciones que analizan los escritos avilistas, que siempre han sido enfocados desde una perspectiva eminentemente espiritual. $Y$ es que abogo por la unificación de la mística y la ascética, a pesar de una larga tradición, prácticamente general, que ha propugnado su total distinción. Siguiendo este argumento dice claramente Baldomero Jiménez Duque: «Separar el estudio de lo ascético y de lo místico es muy difícil y expuesto a reiteraciones inútiles. Ello se viene haciendo, sin embargo, desde finales de la Edad Media [...] Ese uso de distinguir entre la ascética y la mística se mantiene hasta el s. XX, en el que, desde diversos sectores se opera una reacción que propugna por su unificación. Las razones que lo explican son diversas: un estudio de los textos bíblicos en los que se advierte la profunda unidad de la vida cristiana; la percepción de que la separación entre ambas materias -aunque sea sólo metodológica- dificulta la profundización en ellas y se expone a un esquematismo excesivo» ${ }^{11}$. En este sentido, creo que San Juan de Ávila es un paradigma que contiene en sí todos los aspectos místicos y ascéticos en una equilibrada conjunción.

La ascesis, en definitiva, representa, por así decir, la búsqueda, mientras que la mística sella esa búsqueda: verdad esta que puede desprenderse del símbolo de la cruz. Las dos trayectorias marcadas por esta representan las dos dimensiones del acontecimiento salvífico de comunión que en ella se consuma. Por una parte está el palo clavado en la tierra, es decir, en la historia de los hombres; el otro extremo del palo, sin embargo, apunta hacia lo alto, toca idealmente el cielo, porque sostiene al crucificado por amor, reuniendo en sí la realidad humana y la infinitud de Dios. El eje transversal de la cruz abarca y celebra así el misterio de la muerte y de la vida, las dos caras indisolublemente unidas de la ascesis y de la mística ${ }^{12}$.

10. M. Andrés Martín, San Juan de Ávila. Maestro de espiritualidad, Madrid 1997, 90.

11. B. JimÉnez DuQUe, «Ascetismo», en Gran Enciclopedia Rialp, II, Madrid 1971, 148.

12. L. Borriello, «Ascesis-ascética», en AA.VV., Diccionario de Mística, Madrid 2002, 235 s. 


\section{Pedro Cayón Cagigas}

Por otra parte, no se debe soslayar el hecho de que si bien es verdad la afirmación de que por la doctrina avilista no pasa el tiempo y es un filón moral inagotable a través de los siglos, también lo es que se requiere un inevitable ejercicio de adaptación, si queremos hacerlo realidad en nuestra época, acorde con la Iglesia y la sociedad en general, en sus inexorables cambios en el suceder del tiempo, lo que, por otra parte, excede las pretensiones de este artículo.

El presente trabajo surge de un estudio directo de muchos de los escritos de San Juan de Ávila. Ese es el aval indiscutible que demuestra su preocupación por el aspecto cristiano de la vocación. Pero si alguna fuente habría que resaltar en este aspecto de entre todas, esa es el Epistolario. Son abundantes las cartas, entre las numerosas que escribió y han llegado hasta nosotros, donde aconseja sobre este aspecto vocacional de forma explícita a múltiples personas en sus diversos estados, proponiéndolas un programa de vida cristiano para el correcto desempeño de su vocación.

En una primera parte de la exposición veremos cómo se enfoca en los escritos avilistas la vocación cristiana en sus fundamentos, es decir, el hecho de la relación entre Dios y el hombre, o sea, la llamada o invitación divina y la respuesta personal. En una segunda parte abordaremos cuáles son los diferentes estados de perfección, con los medios característicos de cada uno propuestos por el Maestro Ávila, en que se puede explayar esa vocación.

\section{LA LLAMADA DE DIOS}

La Constitución dogmática Gaudium et spes del Concilio Vaticano II define la fe cristiana como una vocación ${ }^{13}$; más aún, descubre que la grandeza del hombre deriva precisamente, de esa iniciativa divina: «Dios ha llamado y llama al hombre a adherirse a Él con la total plenitud de su ser en la perpetua comunión de la incorruptible vida divina ${ }^{14}$.

La teología, por otra parte, explica la fe como «una llamada de Dios»; es decir, la fe tiene una estructura dialogal: Dios inicia el diálogo y el hombre responde. De esta manera «revelación» y «vocación» tienen la misma estructura teológica: la «vocación» deriva de la «revelación» ${ }^{15}$.

Queriendo abarcar de forma rápida y sucinta todo el razonamiento sobre la vocación, se llega a esta definición: la vocación es la llamada que Dios hace sentir al hombre que ha elegido y al que destina a una obra particular en su designio de salvación ${ }^{16}$.

13. Cf. Concilio Vaticano II, Const. past. Gaudium et spes, 11.

14. Ibid., 18.

15. Cf. A. Fernández, «Vocación», en Diccionario de Teología Moral, Burgos 2004, 1444.

16. U. Rocco, «Vocación» en: L. RossI-A. VALSECCHI, Diccionario enciclopédico de Teología Moral, Madrid 1986, 1206. 
En este sentido, debemos considerar el aspecto más personal de toda vocación: la llamada interpela la conciencia de cada uno, provocándolo a una respuesta inalienable. En primer lugar, la experiencia vocacional es una llamada al amor ${ }^{17}$; y en segundo lugar, la respuesta es expresión de amor ${ }^{18}$. Recordemos que el concepto de vocación deriva del latín «vocatio», que significa «llamada»19: ello significa la intervención de Dios en la vida de cada persona, desde una llamada a la existencia, hasta la voluntad divina de que cada individuo conduzca su vida de modo que adquiera la perfección a la que ha sido «llamado»" ${ }^{20}$. Para resumir, y como decía Pablo VI, «en el designio de Dios, cada hombre es llamado a un desarrollo, porque cada vida es vocación $»^{21}$. La vocación, en el sentido de llamada de parte divina y de repuesta coherente por parte humana, es la presentación bíblico-existencial que está adoptando actualmente la teología moral22.

En la unión con Dios por amor intervienen Dios que llama y el hombre que responde, el amor de Dios al hombre y la disposición de éste a colaborar con Dios. La unión incluye lo que es y hace cada persona, la pasión de Dios por el hombre y la de éste por Dios. Se trata, pues, de una relación vivencial de tú a tú, como corresponde a enamorados o a unidos en matrimonio. La iniciativa parte siempre de Dios, que llama al hombre al modo del hombre. Por eso el amor es lo más divino y lo más humano. Situar la espiritualidad en el amor es ponerla a nuestro alcance y a la vez divinizarla ${ }^{23}$.

Si profundizamos en la doctrina avilista vemos como Dios llama a todo tipo de personas con la justa palabra y la apropiada proposición, para que retornen al verdadero camino del seguimiento de Jesucristo. Esa llamada divina conlleva el total dejamiento de la vanidad de las cosas del mundo, que como dice el Maestro Ávila es «la desordenación con que los hombres usan del mundo, los malos afectos que al mundo tienen ${ }^{24}$.

\section{Llamada de Dios y cumplimiento de su voluntad}

Dios, según San Juan de Ávila, desde el principio de la creación, ha tenido comunicación con los hombres, enseñándonos los caminos de la virtud. En este sentido, el Maestro Ávila pone el ejemplo del pueblo de Israel, al cual Dios eligió

17. Cf. JuAn Pablo II, Exhort. ap. Familiaris consortio, 7.

18. Cf. Concilio Vaticano II, Const. dogm. Lumen gentium, 41-42.

19. Cf. L. J. O'ConNeLL, «Vocazione» en M. DownEY, dir., Nuovo Dizionario di Spiritualità, op. cit., 1024.

20. Cf. A. FernÁndez, «Vocación» en Diccionario de Teología Moral, op. cit., 1444.

21. PABLO VI, Cart. enc. Populorum progressio, 15.

22. Cf. U. Rocco, «Vocación» en L. Rossi- A. VALSECCHI, Diccionario enciclopédico de Teología Moral, op. cit., 1208.

23. M. AndRÉs MARTín, San Juan de Ávila. Maestro de espiritualidad, op. cit., 91,

24. Jn I, lec. $14^{a}$, líns. 18-20. 


\section{Pedro Cayón Cagigas}

y dio sus preceptos para que hiciesen obras y diesen testimonio de la obediencia que se le debe 25 .

El llamamiento de Dios nos hace perfectos cuando su llamada es bien recibida y nos inclinamos a cumplir los consejos que Él nos enseña, aunque por ello debamos dejar «hacienda, vida y honra». Esto es lo que justifica al hombre, es decir, su radical alejamiento de las cosas del mundo y poniéndole en la perfección, haciéndole muy parecido y semejante a Jesucristo ${ }^{26}$.

Todas las veces que oyérades decir: cobdicia de carne, cobdicia de hacienda, curiosidad de vida, eso sentencialdo por del mundo, no del Padre; porque el espíritu de Dios induce a desechar y huir de la honra y buscar la humildad y huir de la cobdicia y amar a los trabajos, mortificar la carne, a comunicar con los necesitados los bienes propios y a contentarse con poco. Quien esto hace, de Dios es; y quien no, poneldo por bando contrario, porque Dios y mundo contrarios bandos son ${ }^{27}$.

Para el Maestro Ávila, Dios siempre dice al pecador «vuélvete a mí» y, nos enseña que según su experiencia, refleja que hay varios tipos de llamadas con sus respectivas respuestas: los primeros son aquellos a los que llega la llamada de Dios para que se enmienden, pero no vienen ni responden a su invitación: «ansí acullá en las bodas muchos fueron llamados y no vinieron ${ }^{28}$; otros son los llamados a los que advierte Dios que están en mala vida, y esto, como es natural, les estorba para el bien de su salvación, pero, a pesar de que lo ven y conocen, no están dispuestos a que Dios les ayude y salgan de esa mala vida; por último, están aquellos a los que Dios les inspira que vengan a su llamada, por tanto, oyendo y acatando su voz se convierten de sus pecados para caminar según los preceptos que Él manda en orden a su provecho y salvación ${ }^{29}$.

Acuérdese todo hombre a quien Dios ha llamado de aquel día en que le llamó, y verá que entonces le abrió las orejas y ojos para ver y oír; agradezca como si un sordo o ciego sanara; y acordándose, agradézcalo mucho, pues le fue dado don, que le vale más que todas las cosas, pues le fue dada amistad con el Señor, a la cual no puede comparar cosa alguna ${ }^{30}$.

Atención especial merecen para el Maestro Ávila aquellos que se han distinguido siempre por su conducta desviada de los caminos de Dios, y, que, a pesar de ello, son escogidos de un modo privilegiado por Él para su conversión. Dios muestra su favor y magnificencia en aquellos que están más «llagados» y «enfermos». Es ahí donde quiere Dios hacer misericordia para exaltación de su

25. Cf. Sermón 35, parf. 1.

26. Cf. Carta 184, líns. 292-303.

27. Jn I, lec. $14^{\text {a }}$, líns. 11-19.

28. Sermón 8, parf. 8.

29. Cf. Sermón 8, parf. 8. Cf. Sermón 14, parf. 16, 18, 19, 20.

30. Carta 72, líns. 77-82. 
nombre y para su honra, para que sean vistas sus maravillas. Pero, como él mismo dice, esto no es la vía ordinaria, «esto hácese muy pocas veces, hácese con muy pocos, son muy raros los ansí llamados» ${ }^{31}$. Un texto avilista en el cual se manifiesta esa gloria de Dios al llamar a grandes pecadores que a lo largo de su vida le han ofendido en abundancia es el siguiente:

Mas hay un hombre que estuvo tanto tiempo desollando caras, endurecido y olvidado. Dice Dios: aquí quiero hacer misericordias para exaltación de mi nombre y para mi honra y para que se conozcan mis maravillas, que a éste sin debérselo, antes teniéndome enojado, airado y movido para hacer justicia de él; que busca Dios al más llagado, al más enfermo.

- ¿Por qué, Señor, más a éste que al otro? Cata, Señor, que está harto de haceros afrentas y injurias. ¿Para qué a éste?

-Para que sepan que es Dios señor de lo que tiene, y sepan que lo que da es gracia y es merced y misericordia que quiere hacer, y no es deuda ni jornal lo que da y lo que paga y todo lo que con los hombres hace, y que lo da a quien Él tiene por bien, y a quien quiere lo quita. Vocación aquesta es elección como privilegio, como de poder absoluto, convertir un corazón perro y duro. Está grandazo y muy abundoso en misericordia y mercedes. Ésta es la elección de que el evangelio habla ${ }^{32}$.

\section{RespuestA A LA LLAMADA DIVINA}

Obviamente, en el estudio de la vocación resulta tan importante prestar atención a la llamada como a la respuesta. Conviene reseñar que actualmente la palabra «acogida» está desplazando a la palabra «respuesta». Este nuevo concepto presenta una más clara raíz evangélica. La llamada señala un camino e invita a caminar, y la acogida consiste en franquear la puerta para disponerse a recorrer ese camino.

Todos los hombres en general reciben la llamada de Dios y cada uno responde de un modo específico, en función de sus circunstancias y su historia personales; por ello, la primera cualidad de la vocación es la libertad en la respuesta $^{33}$. Si la llamada de Dios al hombre es libre, la respuesta también ha de ser libre, dado que en ese diálogo íntimo se debe respetar la estructura misma de la persona. Por consiguiente, la vocación no es algo que se impone, sino que se descubre.

Ciertamente, Dios llama a los hombres a servirle en espíritu y en verdad. Por ello, quedan vinculados por su conciencia, pero no coaccionados. Pues Dios tiene en cuenta la dignidad de la persona humana, creada por Él, que debe guiarse por su propio criterio y disfrutar de libertad ${ }^{34}$.

31. Sermón 8, parf. 11.

32. Sermón 8, parf. 11.

33. Cf. L. J. O'ConNelL, «Vocazione» en M. DowneY, dir., Nuovo Dizionario di Spiritualità, 1025.

34. Concilio Vaticano II, Decl. Dignitatis humanae, 11. 


\section{Pedro Cayón Cagigas}

El cristiano es un ser libre que intenta conocer el proyecto de Dios sobre su vida. Por todo ello, descubrir la vocación y ser fiel a esa llamada origina en la persona una serenidad que acaba con una cierta ansiedad existencial ${ }^{35}$.

La llamada de Dios resuena en la intimidad de la conciencia, el núcleo más secreto y el sagrario del hombre, donde él se encuentra a solas con Dios. A través de la conciencia, se reconoce la ley moral en sus imperativos y se aplica a las situaciones concretas, en vista de las necesarias elecciones operativas ${ }^{36}$.

Respuesta a la Llamada. Dejemos las cosas del mundo para seguir el llamamiento de Dios

Según el Maestro Ávila, Dios avisa, despierta y llama a todos los hombres para que se conviertan a Él y así puedan alcanzar la salvación. La respuesta personal a la llamada divina se concentra, de acuerdo con su pensamiento, en un total dejamiento de la futilidad de lo terreno para una dedicación exclusiva a las cosas de Dios:

Si las cobdicias del mundo no las queréis dejar, porque no son de parte de Dios mirad que el mundo se pasa y sus concupiscencias; catad que el deseo de la carne que se pasa; la cobdicia de los dineros se pasa; la soberbia de la vida se pasa. Dice San Juan: Para que aborrezcáis eso, esto os doy, por motivo que se pasa ${ }^{37}$.

Cuando se escucha esa llamada divina por parte de la persona, el primer impulso es la acción de gracias, el agradecimiento por tal don recibido. Así se lo aconseja en la Carta 94 a «una doncella que había comenzado a servir a Dios»:

Lo primero, doncella, que me parece que debéis de hacer, es conocer el gran beneficio que de la mano de Dios habéis recebido en haberos dado corazón que desprecie lo presente y haceros amadora de lo que no se ve con estos ojos, ni se oye con estas orejas, ni se toca con estas manos, mas gústase con la limpieza del ánima, y es cosa que más que todas éstas juntas vale sin comparación. San Pablo ruega a Dios que dé a entender a los de Éfeso el grande bien para que son llamados (cf. Ef 1, 16-18); e yo suplico lo memos para vos, para que, conociendo el gran valor de vuestra esperanza, seáis más agradecida a quién os llamó, y holléis de mejor gana estas poquedades de acá, como a quién le diesen oro, de buena gana dejaría el lodo y estiércolis.

Por otra parte, la invitación o el «sígueme» con que el Señor interpela a todo hombre, va unida inexorablemente a una configuración de éste con el estilo de vida de Aquél:

35. Cf. A. Fernández, «Vocación» en Diccionario de Teología Moral, 1445.

36. Conferenza Episcopale ItAliana, L'impegno morale del cristiano, 5.

37. Jn I, lec. $14^{\text {a }}$, líns. 63-67.

38. Carta 94, líns. 12-22. 


\section{Vocación y estados de perfección}

Dice Dios: Sígueme. Si éste tiene hacienda y honra, y vive sin trabajos, ¿no se afrentará, y terná gran dolor de ver a Cristo a su lado pobre y ser él rico, de ver a Cristo lleno de trabajos y él con descanso, de ver a Cristo con una cruz a cuestas y descalzo, y corriendo sangre, y él muy descansado? En verdad, el cristiano que esto siente, sentirá gran dolor de ver que él no puede ir como va su Señor ${ }^{39}$.

No son necesarias grandes voces de parte divina, pues simplemente en los mismos acontecimientos cotidianos, que son los que suelen pasar más desapercibidos, es donde se encuentra un llamamiento dirigido a dejar las cosas del mundo y arrimarse a Dios. Para quienes han recibido ese llamamiento de Dios, esto supone un punto de inflexión en sus vidas; a partir de ese momento todo se transforma, las cosas que tenemos por vitales pasan a un lugar secundario. El ejemplo paradigmático lo pone el Maestro Ávila en San Mateo con su actitud de renuncia a todo lo que definía su vida hasta el momento de ser elegido por el Señor:

Hermanos, despertemos y oyamos la voz de nuestra Madre, oyamos de buena gana el llamamiento de nuestro Padre. No nos hagamos sordos, sigámosle con diligencia, olvidando nuestros negocios, nuestras trampas, nuestros pecados, como hizo este bienaventurado santo [San Mateo], que, luego como oyó la voz de su Pastor y verdadero Padre, luego desamparó todo cuanto tenía y lo siguióo ${ }^{40}$.

San Juan de Ávila hace hincapié de una forma especial en el momento crucial que supone la muerte. Es en este punto de inflexión, que todos experimentamos conscientemente ya aquí en la propia vida en el fallecimiento de terceras personas, cuando Dios se dirige a nosotros para mostrarnos la bajeza de las cosas mundanas. En la muerte se muestra de forma clara el despojamiento inexorable de todo lo temporal, y Dios quiere con ello convencer al hombre para que llegue a dejar lo fútil de las cosas.

No os engañéis, que voz y voces os da y os ha dado en vuestros corazones, y de esto corazón ninguno se puede quejar, que voz del Señor y llamamiento y aviso es ver enterrar a tu amigo, a tu pariente, a tu conocido, al que amabas, al que era más mozo que tú, al más rico que tú, al más alto, al más poderoso; y en esto te dije que aquello que ves en aquél será de ti y pasará por $\mathrm{ti}^{41}$.

Este recurso de "escarmentar en cabeza ajena» es utilizado profusamente a lo largo de toda su producción teológico-espiritual. También lo podemos encontrar como muestra en la Lección $14^{a}$ a la Primera canónica de San Juan:

No era menester que esto se dijese por muchas palabras, viendo lo que vemos. ¡Cuántos habrán andado por esta tierra donde nosotros andamos! ¿Qué fue de

39. Jn I, lec. $14^{\text {a }}$, líns. 277-283.

40. Sermón 77, parf. 12.

41. Sermón 77, parf. 12. 


\section{Pedro Cayón Cagigas}

ellos? Ya se pasaron. ¡Qué cosa ver favores de cortes, justas y torneos, invenciones, faustos y atavíos! Espera un poquito, ¿qué se hicieron? [...] Y plega a Dios que lo entendamos y que escarrmentemos en cabeza ajena ${ }^{42}$.

Y otro aspecto que aparece en los escritos del Maestro es la espera de la visión de Dios tras partir de este mundo como reafirmación de que todo lo mundano es caduco. El Señor que nos llama será nuestra «joya y premio», pero para ello debemos confiar en su llamada y en los beneficios que nos esperan. Como ya se ha dicho, con esta seguridad en lo divino superaremos las cosas terrenas y las tendremos por despreciables al lado de la visión de la divinidad:

Mis ojos, que han de ver a Dios, no es razón que vean vanidades; lengua que ha de alabar a Dios, no es bien que se ocupe en murmurar; cuerpo y alma que ha de gozar de Dios, no es justo que revuelque en el cieno. Si entendiésemos que hemos de ir al cielo, ese caso haríamos de lo próspero que de lo adverso. ¿Qué se me da de riquezas, pues espero las riquezas del cielo? ¿Qué se me da de trabajos, pues se han de acabar presto y luego he de ir a descansar? ${ }^{43}$

\section{EL IDEAL DE PERFECCIÓN}

El Concilio Vaticano II insiste en la igual dignidad de todo cristiano en algo decisivo: la vocación a la santidad y a la perfección. En toda la vida de la Iglesia se refleja la diversidad de dones, carismas y de funciones. Cuando hablamos de «ideal de perfección» nos referimos a los diferentes estados de vida que están llamados a la perfección, o mejor, a la santidad, según terminología más reciente surgida a partir de dicho Concilio ${ }^{44}$.

Como ya se dijo anteriormente, este estudio se fija esencialmente en el aspecto ascético que aparece de forma prominente en los textos avilistas. La ascética ha sido tradicionalmente la parte de la teología moral que trata de la perfección cristiana y comprende todos los medios para conseguir ese objetivo, y está arraigada profundamente en la Sangrada Escritura y en toda la tradición de la Iglesia. La ascética ha sido siempre un trabajo espiritual de conquista progresiva de las virtudes. Por otro lado, es necesario señalar que ese camino ascético no tiene su fin en los medios específicos de ascesis, sino que su fin es el seguimiento de Cristo a través de éstos, donde el esfuerzo humano no podría tener eficacia ni valor si no se apoya enteramente en la gracia divina.

Hemos de afirmar en sano humanismo cristiano que la tarea de la perfección del hombre la inicia, la acompaña, y la consuma Dios. Pero el hombre toma parte en ella activa y libremente. Sin el «concurso» divino nada es posible, y menos sobre-

42. Jn I, lec. 14a , líns. 69-73, 82-83. Cf. Sermón 82, parf. 25.

43. Sermón 18, parf. 11.

44. Concilio Vaticano II, Lumen gentium, 3; también, Juan Pablo II, Veritatis splendor, 18. 


\section{Vocación y estados de perfección}

naturalmente hablando. Pero, bajo la gracia, el hombre actúa. Y esa actuación suya le es fácilmente registrable bajo todos los aspectos, así como la actuación divina de suyo se esconde a su conciencia, aunque se le revela la fe. La parte del hombre en esta sinergia divino-humana es la que llamamos ascética en un lato sentido ${ }^{45}$.

Por otro lado, la ascética, no es, el fin último de la vida cristiana, sino una mediación instrumental para alcanzar la unión con Dios Padre ${ }^{46}$. En este sentido, la ascesis cristiana tiene un aspecto positivo y gozoso, por cuanto no es pura privación, y menos aún un aniquilamiento de algo humano, sino que significa la ayuda para quitar los obstáculos que impiden que el hombre alcance la existencia que le corresponde en su condición de hijo de Dios en Cristo: llegar a ser otro Cristo $(\mathrm{Gal} 2,20)^{47}$. Por tanto, el último objetivo es el acontecimiento pascual, punto de partida de toda ascética cristiana.

La ascesis cristiana sólo es auténtica si se sitúa dentro del horizonte del misterio pascual. Por este motivo, la ascesis del cristiano sólo puede ser en su significado más profundo participación en la ascesis de Cristo, y por consiguiente ascesis de cruz. Esta participación, libre y voluntaria, en la muerte salvífica de Cristo, establecida como fundamento en el bautismo, ha de ser continuamente aceptada de nuevo y hacerse explícita en un morir continuo con Cristo (cf 1 Cor 15, 31; 2 Cor $4,10-12$ ). En esta perspectiva ascética se puede hablar de la vida cristiana como acontecimiento pascual cuando en los surcos de la historia cotidiana los actos de renuncia y de superación de uno mismo constituyen una "pascua», es decir, un paso de la muerte a la vida, la realización de la iniciación bautismal, que es esencialmente la vivencia concreta de la pascua del Señor en cada uno de los miembros de su cuerpo. Sólo dentro de esta perspectiva, la ascesis cristiana, lejos de caer en una sospechosa afición al dolor, sigue siendo un esfuerzo de liberación en la muerte del pecado ${ }^{48}$.

Presentaremos ahora la descripción de cada estado de vida y los medios de ascesis que propone el Maestro en consecución a la perfección cristiana.

\section{Estado laical}

No puede dudarse de que la preocupación de San Juan de Ávila está en los sacerdotes, por la necesidad de presbíteros formados y santos que requería vigorosamente la Iglesia de su momento, pero también se puede contemplar su doctrina desde un punto de vista laical ${ }^{49}$, descubriendo en ella múltiples valores. En este sentido, señala Esquerda Bifet que «la doctrina sistemática actual sobre

45. B. JimÉnEZ Duque, «Ascetismo», en Gran Enciclopedia Rialp, op. cit., 146.

46. Cf. L. Borriello, «Ascesis-ascética», en AA.VV., Diccionario de Mística, op. cit., 228.

47. Cf. A. FernÁdeZ, «Ascesis», en Diccionario de Teología Moral, 119.

48. L. Borriello, «Ascesis-ascética», en AA.VV., Diccionario de Mística, 228.

49. Para profundizar, cf. L. SUÁREZ FERNÁNDEZ, «San Juan de Ávila, maestro también de laicos», en AA.VV., El Maestro Ávila. Actas del Congreso Internacional, Madrid 2000, 731-742. 


\section{Pedro Cayón Cagigas}

el laicado no existía en el siglo XVI. En la doctrina avilista se hace resaltar, con la llamada a la santidad de todos los bautizados, la participación en el sacerdocio de Cristo ${ }^{50}$. Es evidente, por ejemplo, que en todo el Sermonario hay una llamada general a la santidad, pero también son de notar cartas particulares donde vemos una invitación a la renovación personal, al seguimiento de un genuino estilo de vivir cristiano, dirigida a personas concretas que pertenecen a diferentes estamentos dentro de la sociedad, reflejando así una inquietud latente hacia este sector laical.

Concretamente, en los Escritos menores se encuentran varias listas de consejos para aparejarse a vivir la vocación cristiana desde el estado laical. Tomo preferentemente la primera ${ }^{51}$, una Breve regla de vida cristiana, compuesta por el Maestro Ávila, que apareció en 1556 como apéndice en la primera Guía de pecadores del P. Granada. De esta regla se pueden entresacar diez pautas fundamentales que enseña el Maestro para todo aquel que quiera andar por el camino de la fe. Son de notar las continuas y muy acertadas referencias bíblicas que acompañan a dicho escrito.

1. Se han de tener dos ratos de oración al día, preferentemente uno a la mañana y otro a la noche. El de la mañana estará dedicado a la meditación de la pasión de Nuestro Señor, y el de la noche a acordarse del momento de la muerte, «así cumplirá el consejo de la santa Escritura, que dice: Acuérdate de tus postrimerías, y no pecarás jamás (Eclo 7,40$) \varkappa^{52}$.

2. Trabajar por tener siempre en la memoria algún buen pensamiento, «porque el demonio le halle siempre ocupado y ande siempre con una memoria que Dios le mira» ${ }^{53}$.

3. Confesar y comulgar a menudo, «por imitar aquel santo tiempo de la primitiva Iglesia, cuando comulgaban de ocho a ocho días los fieles» ${ }^{54}$.

4. Ser generoso para pasar trabajos y tribulaciones al estilo del Señor, que dijo: Si a mí persiguieron, a vosotros perseguirán (Jn 15, 20). «Para que, estando así armado, no le aparten de sus buenos ejercicios las malas lenguas ni los contrarios que dondequiera ha de hallar» ${ }^{55}$.

5. Poner la atención en las propias faltas y no en las ajenas. Todo conforme al dicho del Señor: Hipócrita, ¿por qué miras la paja en el ojo de tu hermano y no consideras tú la viga que tienes atravesada en el tuyo? (Mt 7, 3). «No tenga cuenta más de con sus propios defectos, y, si algo viere en el prójimo digno de ser re-

50. J. Esquerda BIfET, Introducción a la doctrina de San Juan de Ávila, op. cit., 440-443.

51. La primera Regla es la más dinámica y profunda, y podríamos decir que está destinada a un público más amplio. Le sigue Reglas muy provechosas para andar en el camino de nuestro Señor, pero son muy extensas, exactamente 32, y no tienen la originalidad primaria del autor. Por último, los Diez documentos, que son una corrección posterior de la primera.

52. Reglas de Espíritu, 1, p. 839.

53. Reglas de Espíritu, 1, p. 839.

54. Reglas de Espíritu, 1, p. 840.

55. Reglas de Espíritu, 1, p. 840. 
prehensión, no se indigne contra él, sino compadézcase de él, porque la santidad verdadera dice San Gregorio ${ }^{56}$ que es compadecerse de los pecados, y la falsa, indignarse contra ellos $»^{57}$. Esto no obsta para que el Maestro Ávila promueva la corrección fraterna y la oración al Señor para que aplaque los pecados.

6. Hacer caridad a los prójimos, acordándose de la sentencia de Jesucristo: En esto conocerán todos si sois mis discípulos, si os amárades unos a otros (Jn 13, 35). También se aconseja rogar a Dios por la Iglesia, a la que redimió.

7. Pedir siempre al Señor la perseverancia. En esto se ha de acordar de aquel pasaje que dice: El que persevere hasta el fin será salvo (Mt 10, 22; 24 , 13). «Y así quite siempre los ojos del bien que hiciere y póngalos en lo que le queda por hacer, para que lo hecho no le ensoberbezca y lo por hacer le ponga humildad y cuidado de pedir a Dios gracia para cumplirlo (cf. Mt 24, 12)» ${ }^{58}$.

8. Buscar en todas las obras la gloria de Dios, y no el propio provecho. Esto sea conforme al consejo de San Pablo: Ahora comáis, o bebáis, o hagáis otra cualquier cosa, todo lo haced para la gloria de Dios (I Cor 10, 31). "Y así, pretendiendo sólo esto, no le desconsolará mucho la sequedad que a muchos desconsuela y hace aflojar en el servicio de Dios, habiendo de ser entonces más diligentes en la guarda de sí mismos y más solícitos en escudriñar si han hecho algún pecado por el cual el Señor los dejase así desconsolados» ${ }^{59}$.

9. Huir de las compañías que no traen ningún provecho. Para el Maestro Ávila, según dice el profeta: La garganta de los malos es como una sepultura abierta (Sal 5, 11). "Y por esto, siempre debe huir la compañía de los tales, porque, si en ello mira, nunca hablan sino palabras conformes a la muerte que sus ánimas dentro de sí tienen, $\mathrm{y}$, a lo mejor librar, cuando las palabras son cuerdas al parecer de ellos, entonces son nocivas al prójimo, diciendo mal y murmurando [...] porque dice San Bernardo ${ }^{60}$ que duda cuál peca más, el que murmura o el que oye de buena gana murmurar» ${ }^{61}$.

10. Obrar bien, poniendo siempre los ojos y confianza en los merecimientos de Cristo. «Quiero decir que el valor de nuestras obras nace de los merecimientos de Jesucristo y de la gracia que por Él se nos da. Así debe lanzar toda soberbia y vanagloria de su corazón, por muchas obras buenas que le parezca hacer, porque, si bien mira en ello, hallará que, por la mayor parte, todo cuanto hace va mezclado de mil imperfecciones, por donde más tenemos por qué pedir perdón al Señor por la mala manera de obrar que por donde esperar galardón por la substancia de las obras» ${ }^{62}$.

56. San Gregorio Magno, Moral. I.26 c.6, 6: ML 76, 352.

57. Reglas de Espíritu, 1, p. 841.

58. Reglas de Espíritu, 1, p. 841.

59. Reglas de Espíritu, 1, p. 842.

60. SAN BERNARDO, Liber de modo bene vivendi 17, 48: ML184, 1229s.

61. Reglas de Espíritu, 1, p. 842.

62. Reglas de Espíritu, 1, p. 843. 


\section{Pedro Cayón Cagigas}

\section{Estado religioso}

San Juan de Ávila profesó siempre hacia la vida consagrada un afecto especial, pues para él suponía el apego radical a las exigencias evangélicas. No extraña, por tanto, que en el Sermón 27 diga: «¿Sabéis qué son los religiosos en el cuerpo místico de la Iglesia? El Papa es la cabeza; los brazos, los caballeros; el corazón, los religiosos. Él es el primero que vive y el postrero que muere; él es la fuente del calor, él es el que está más guardado» ${ }^{63}$.

Carecemos de criterios específicos del Maestro Ávila dirigidos a religiosos, pues las diferentes Reglas de éstos se presuponen como motor para el desarrollo del proyecto de vida religiosa específico de cada uno. No obstante, contamos con la Carta 224 del Epistolario dirigida a una doncella que quería entrar en estado religioso. De esa carta entresacamos lo que el Maestro pensaba acerca de tal vida. Se centra en los consejos evangélicos, es decir, los tres votos de pobreza, castidad y obediencia, que constituyen la esencia de la vida religiosa. Sintetizaré dicha carta en dos ideas principales:

1. Profundo amor a Cristo, dejando de lado las cosas perecederas y transitorias del mundo. Para la conservación de este amor en el corazón se proponen tres medios: primero, la pobreza: «la cual alimpia el corazón de la afición de las cosas exteriores; y no tan solamente basta guardarla en lo interior, mas es menester guardarla de tal manera que la esposa de Cristo no tenga, ni menos quiera tener, sino aquello que es necesario para vivir» ${ }^{64}$; segundo, la castidad: acude a San Agustín ${ }^{65}$ para decir que «entre todas las batallas de los cristianos la más dura es la castidad, en la cual hay continua guerra y rara victoria, y mucho más trabajosa a los mancebos y doncellas, y tanto mayor cuanto más de hecho y de corazón querrán ser castos» ${ }^{66}$; y tercero, la obediencia: «la cual alimpia el alma de las desordenadas aficiones espirituales. Y para haber de guardar esta obediencia, es menester conformarse con Jesucristo, el cual fue hecho obediente hasta la muerte, y muerte no cualquiera, sino muerte de cruz (FIp 2, 8)» ${ }^{67}$.

2. Para conseguir ese triple proyecto una cosa sola es necesaria: la continua oración. «Y al bordón que más se ha de arrimar para andar ese camino ha de ser la continua oración, porque el alma que no orare será traída en tentación y caerá a cada paso, y la esposa de Cristo será hecha bestia. Y de cómo nos conviene y es necesario orar, tenemos palabra de Cristo, que nos lo manda, diciendo: Velad y orad, no entréis en tentación (Mt 26, 41) ॥ ${ }^{68}$. Esta oración se ha de procurar con soledad, silencio y recogimiento en los tiempos debidos y ordenados.

63. Sermón 18, parf. 19.

64. Carta 224, lins. 50-53.

65. San Cesareo de Arlés (entre las Obras de San Agustín), Serm. 293, «De honestate mulierum» 2: ML 39, 2302.

66. Carta 224, lins. 122-125.

67. Carta 224, lins. 260-263.

68. Carta 224, lins. 303-308. 


\section{Vocación y estados de perfección}

\section{Estado presbiteral}

Tema tradicionalmente tratado por los estudiosos de San Juan de Ávila es el presbiterado, y ello debido a la gran riqueza doctrinal sobre el sacerdocio ministerial que se encuentra en los escritos avilistas. El s. XVI era una época de profunda reforma a nivel de costumbres dentro del clero, y el Maestro Ávila cobró un papel muy destacado en pro de su eficaz ejecución ${ }^{69}$, y toda su obra así lo demuestra. El Maestro estuvo siempre solícito a dirigir pautas de comportamiento moral, espiritual e intelectual a todos los sacerdotes que a él acudían, precisamente por la situación de relajamiento en la que habían caído muchos de ellos. El origen de dicha situación moral imperante la ha reflejado bien Juan Esquerda Bifet cuando dice que «algunos entraban a formar parte de este estado de vida (por medio de la «tonsura») sólo para conseguir privilegios y sin ninguna selección y preparación» ${ }^{70}$.

Este pésimo ambiente clerical lo manifestó numerosas veces el Maestro en sus escritos, y son palabras que no dan lugar a dudas sobre la indiscutible necesidad de reforma. En su Tratado sobre el sacerdocio, texto eminentemente dedicado a la renovación sacerdotal, encontramos el siguiente comentario: «cuán caída está la Iglesia en esta parte tan principal de ella como es el sacerdocio, cuán deturpada su faz, cuán ciegos sus ojos, cuán muda su lengua y cuán poco socorro de oración dan a la Iglesia los que lo tienen por oficio y obligación [...] Y, aunque algunos sacerdotes haya que hagan su oficio medianamente, mas aun éstos faltan de su alteza que esta dignidad pide; y son tan pocos en comparación de los malos, que la mejor parte es vencida de la mayor $\rangle^{71}$.

Como ya se ha dicho arriba, he querido centrar este apartado en determinados aspectos que quizá no han sido habitualmente tan estudiados, como son las actitudes ascético-morales que según el Maestro han de adornar al sacerdote en el desempeño de su ministerio.

\section{Programa de formación intelectual-espiritual}

San Juan de Ávila siempre advirtió de lo nocivo que suponía para la Iglesia la falta de preparación de sus presbíteros, por ello abogó siempre por una formación permanente. En las Advertencias al Concilio de Toledo señala en el n. ${ }^{\circ}$ 43 la adecuada formación en los seminarios, y en el número siguiente hace un comentario sobre el lamentable estado intelectual de los presbíteros de la época, diciendo: «lo dicho es para criar de nuevo buenos sacerdotes; y no basta, si no procuramos remediar los muchos ya criados que hay, cuya ignorancia es mucho

69. Obra de referencia sobre el papel que jugó el Maestro Ávila en la reforma del clero del s. XVI es: F. SÁnchez Bella, La reforma del clero en San Juan de Ávila, Madrid 1981.

70. J. EsquerdA BIFET, «Clérigos», en: Diccionario de San Juan de Ávila, Burgos 1999, 176.

71. Tratado sobre el sacerdocio, 35 . 


\section{Pedro Cayón Cagigas}

de llorar a los que la experimentan y saben cuán necesario es el provecho de las almas todas, pues ellos son la guía de ellas» ${ }^{72}$.

Como remedio a esa situación, el Maestro recomienda un estudio profundo del Nuevo Testamento, incluso "sería bien sabello de coro» ${ }^{73}$, "y no se meta sino en saber el sentido propio que el Señor quiso allí entender» ${ }^{74}$. Para cuando el sentido de la Escritura exige un comentario de otras fuentes, remite a Nicolao ${ }^{75}$, Jerónimo, Crisóstomo y las Paraphrasis ${ }^{76}$ de Erasmo («con condición que se lean en algunas partes con cautela; en las cuales será, luego, cuando discrepa del sentido común de los otros doctores o del uso de la Iglesia» ${ }^{77}$ ). Sobre el conocimiento del Nuevo Testamento recomienda saber griego, por poco que sea. A este respecto aconseja las Anotationes, también de Erasmo de Róterdam. Después del estudio del Nuevo Testamento, el Maestro Ávila escribe que aprovechan mucho los libros de los Proverbios, el Eclesiástico, los Profetas, etc. ${ }^{78}$

En cuanto a «libros devotos» recomienda como principales a San Bernardo, sobre todo su obra In Canticis $^{79}$, y a Casiano, en De Collationibus patrum y De octo vitiis ${ }^{80}$; otros son: Passio duorum; Abecedario espiritual de Francisco de Osuna; De duodecim mortificationibus de Henrico Herpio; Contemptus mundi; San Juan Clímaco; Morales de San Gregorio; Meditaciones Augustini et Bernardi.

Respecto a los escolásticos, recomienda a Gabriel Biel ${ }^{81}$ y la Suma Cayeta$n a^{82}$. Pero hace hincapié en la oración más que en el estudio, y así dice lo siguiente a un discípulo: «Digo que no es mi intención de ahogalle tanto con lección, que más querría velle vivir con oración, mas doile recepta para muchos días, la cual ha de ir obrando poco a poco y con libertad de corazón» ${ }^{83}$.

Otra recomendación es la realización de un «cartapacio» para ordenar máximas como las siguientes: «Sobre el amor de Dios, el amor al prójimo, sobre la abstinencia, sobre la blasfemia», "y lo que hallare en lo que leyere, ansí en la Sagrada Escriptura como en los santos» ${ }^{84}$.

Para terminar, una muestra de cómo el Maestro Ávila se interesó vivamente por la formación de los clérigos. Así, en Algunas advertencias al sínodo de To-

72. Advertencias al Concilio de Toledo, 44.

73. Carta 225, lín. 14. Cf. Carta 5, lín. 107.

74. Carta 5, lins. 111-112.

75. NICOLÁS DE LYRA, Biblia sacra cum glossis interlineari et ordinaria, Nicolai Lyradi postilla et moralitatibus, Lyón 1545.

76. ERAsmo, Paraphrasis in Ev. Matthaei; In Ev. Marci Paraphrasis; In Ev. Lucae Paraphrasis; Erasmo Roterodami Paraphrasis in Ev. sec. loannem, Alcalá 1525.

77. Carta 225, lins. 17-20.

78. Cf. Carta 225, lins. 21-26.

79. San Bernardo, Serm. in Cantica: ML 183, 785-1198.

80. CASIANO, L., Collat:: ML 49, 478-1320; Collat. V: De octo principalibus vitiis: ibid. 609-642.

81. GABRIEL BIEL, Epitoma pariter et collectorium circa IV Sententiarum libros, Basilea 1512.

82. Summula peccatorum, Romae 1925.

83. Carta 225, lins. 37-40.

84. Carta 225, lins. 84-85. 


\section{Vocación y estados de perfección}

ledo, dice: «Provéase que los clérigos tengan libros devotos en que leer y libros de casos de conciencia en que estudiar, y Biblia, pues éstas son sus armas, que, como capitales de los pueblos, han de tener. Y, pues el rey hace alarde de las armas de sus caballeros y se las manda tener, y castiga a los que no las tienen, justo es que los obispos manden a sus clérigos tener las suyas y que hagan de ellas alarde; quiero decir sean examinados y visitados si las tienen, pues son armas más fáciles y menos costosas que las de los seglares» ${ }^{85}$.

\section{Programa cotidiano de vida ascética}

Por parecerme imposible hacer un esquema íntegro de todas las recomendaciones que realiza San Juan de Ávila a cada sacerdote o discípulo, debido a la nutrida cantidad de aspectos y matices que se encuentran, y que por otra parte son interesantes de reseñar, paso a detenerme en varias cartas del Epistolario. Para una mayor dinamicidad desglosaré las recomendaciones que realiza el Maestro Ávila a los sacerdotes según los momentos del día, o los cambios sustanciales de actividad. Al final realizaré una especie de balance, o denominador común, de lo que debe ser la vida del sacerdote en sus diferentes aspectos según el Patrono del Clero español.

En la Carta 5, dirigida al Mtro. García Arias, sacerdote dedicado al estudio de la teología, le ofrece los siguientes consejos:

1. Llegando a la última hora de la tarde recogerse, y de rodillas rezar el Confiteor Deo y el salmo Miserere mei; confesar al Señor los pecados, pidiendo misericordia por el sacrificio de la Pasión de su Hijo. Hecha la señal de la cruz, y en la postura que mejor le pareciere, meditar sobre su propia muerte, «como si en ella estuviese... Y pues esto ha de venir, haga cuenta que ha venido, y dése por muerto a este mundo, volviendo de verdad las espaldas y echando de su corazón toda criatura, y todo amor de honra, y todo temor de deshonra; y haga cuenta ya está en el otro mundo, y viva acá como en una inmutabilidad entre las mudanzas, mirando cómo ya es todo pasado, y él y los que ve están ya olvidados, y todo se ha ya pasado, ansí como agua que corrió con zurrido» ${ }^{86}$.

Posteriormente, le recomienda que medite cómo su alma será puesta en juicio delante de Dios. Debe pensar y sentir como será acusado por todos sus pecados pasados; esto le debe llevar a pensar en lo poco agradecido que ha sido para con Dios, que le ha dado todo desde el principio. Lo siguiente será pasar a realizar el examen de los defectos en que ha caído ese día, sintiéndolos y pidiendo luz al Señor para el conocimiento propio.

2. Después de realizados estos ejercicios, que durarán en torno a dos horas, pasará a cenar, y como dice el Maestro Ávila: «coma un bocado de cosa liviana,

85. Algunas advertencias al sínodo de Toledo, 97.

86. Carta 5, lins. 20.26-33. 


\section{Pedro Cayón Cagigas}

porque así ha de ser la cena, que en ninguna manera dé pesadumbre al ánima, para entender en la oración $»^{87}$. La cena ha de ser en silencio, el cual durará hasta celebrar la eucaristía al día siguiente. Tras la cena se ha de rezar algo vocalmente y leer algún texto que lleve a devoción, para pasar a aparejarse a dormir, que se hará pensando cómo ha de ser su propia sepultura y la que fue del Señor.

3. Pasadas cinco horas de haberse acostado, levantarse y rezar Maitines. Hecho esto, pensar, hincadas las rodillas, en la Pasión del Señor, tomando para cada día un paso de ella. Esta meditación se prolongará por dos horas, pasadas las cuales podrá dormir durante una hora, u hora y media. Después deberá rezar Prima, Tercia y Sexta, y disponerse para celebrar la misa pensando en lo profundo de este misterio. Se debe pensar en la misa de la misma forma que se meditó sobre el Señor en la oración. Después de la misa se recogerá media hora para dar gracias «y holgarse con Aquél que en sus entrañas tiene» ${ }^{88}$.

4. A partir de ahí comenzará el estudio, durante dos horas, hasta la comida. Después de comer ha de holgar un poco el pensamiento «que, aunque parece que cuando pican la piedra del molino no se hace nada, mas mucho se hace en aparejarla para más moler. Y si su cabeza ha menester un poquito de sueño, tómelo enhorabuena» ${ }^{89}$. Después se ha de rezar Nona, Vísperas y Completas.

5. La tarde se ha de gastar en provecho de los prójimos: visitar a todo tipo de enfermos, sobre todo los más graves; intentar reunir a los que están en discordia; dar catequesis de buenas costumbres a los jóvenes, utilizando los textos de Tulio o Platón. Y así se acabará la tarde, empezando otra vez con los consejos ya dichos arriba.

En la Carta 8, dirigida a un sacerdote, le aconseja las siguientes pautas en la organización de cada jornada:

1. Que por la noche tenga presente las palabras de Mt 25, 6: «iQue llega el novio, salid a recibirlo!», para que nos tenga siempre ocupado el corazón ese Huésped divino que ha de venir en la Eucaristía del día siguiente. A la mañana, con esta consideración ha de rezar sus Horas; posteriormente en estado de reposo, durante hora y media, debe considerar quién es el que ha de recibir, sintiendo indignidad por ser tan pecador. Después ha de presentar sus pecados pasados y presentes: «y como enfermo que enseña sus llagas al médico, pídale conocimiento y salud para ellas $»^{90}$.

2. Hecho esto se celebrará la eucaristía, ofreciéndola por las personas particulares de las que tiene obligación y por la Iglesia Católica en general, acordándose de cómo se ofreció el Señor en la cruz por el mundo. Para el Maestro

87. Carta 5, lins. 70-72.

88. Carta 5, lin. 98-99.

89. Carta 5, lins. 113-116.

90. Carta 8, lins.34-35. 
Ávila la misa tiene diversas intenciones según el día: «La misa se dirá el lunes por las ánimas de purgatorio; martes y miércoles, por quien quisiere o fuere en cargo; jueves, viernes, sábado [y] domingo, por la reformación de las costumbres de la Iglesia ${ }^{91}$. Concluida la misa, se ha de recoger entre media hora y una, para dar gracias al Señor por su venida a un huésped tan indigno. Entonces meditará sobre algún paso del Evangelio donde el Señor hizo algún beneficio, como curar algún enfermo o libró a los discípulos de la tempestad del mar.

3. Desde ese momento hasta la comida, puede leer algo y rezar las Horas que faltan. Después de comer y dormir rezará las Horas y leerá otro poco, teniendo además algo de oración disfrutando en la consideración de como en ese día Dios ha sido su huésped.

4. Seguirá algún ejercicio corporal hasta la hora de Vísperas. Después leerá otro rato, para luego visitar a algún enfermo o alguien que nos haga provecho.

5. A la noche debe haber otro espacio de hora y media para rezar Completas y leer, sobre todo si está indevoto; luego debe pensar en la hora de la muerte y en el juicio de Dios, acusándonos de los pecados pasados y presentes. Mirar cuánto ha hecho Dios por nosotros y lo poco que nosotros lo hemos servido y agradecido. Este debe ser un examen de conocimiento propio.

Otra carta donde se propone un programa de vida es la Carta 162. El sacerdote a la que va dirigida está en estado de tibieza, y como remedio San Juan de Ávila propone varios consejos que la superen, que desmenuzo en las siguientes ideas fundamentales:

1. Mezclar en todas las ocupaciones la memoria y presencia de Dios. Le aconseja un recogimiento que no se pierda en los diversos negocios del mundo.

2. En la oración buscar la comunicación con el Señor, intentando por todos los medios que la mente no vague. Pensar en un sentenciado a muerte o en el mismo juicio de Dios, donde el acusado, en esa situación límite, lo único que piensa es en decir: «Rogad por mí»»

3. Antes de acostarse, se debe leer un libro devoto o tomar una disciplina. Orar vocalmente: decir algunas palabras espirituales, sacadas de la afección propia del corazón, de los salmos o de alguna otra fuente, en prosecución de un buen sentimiento.

4. Guardarse de los pecados veniales, que apagan el fervor de la caridad y pedir al Señor espíritu de devoción.

5. Determinarse en guardar siempre estos ejercicios, estando seco o devoto. Perseverar diciendo: «Yo no vengo aquí sino porque el Señor lo manda y por estar en cruz como Él estuvo»» ${ }^{93}$.

91. Carta 8, lins. 49-51.

92. Carta 162, lins. 20-29.

93. Carta 162, lins. 43-45. 


\section{Pedro Cayón Cagigas}

En la Carta 225, después de realizar las recomendaciones de tipo intelectual llega al aspecto ascético-espiritual. Antes de comenzar debemos de tener en cuenta que este discípulo padece problemas de salud, cosa que verifica con alguna afirmación que veremos:

1. Comienza sus indicaciones a partir de la última hora de la tarde, como dice propiamente el Maestro Ávila: «tocando al Ave María»; ese momento se dedica al recogimiento y la lectura de algún libro devoto, pasando después a la oración, constituida por el examen de conciencia del día y la meditación sobre la propia muerte y el juicio final. Pasada una hora, u hora y media, volverá a la lectura del Nuevo Testamento, para después pasar a cenar «un poquito». Después de realizada la cena se rezará vocalmente durante un breve tiempo y se pasará a la meditación de la Pasión de Jesucristo, tomando un paso para cada día de la semana, acompañada de algún libro devoto tocante a dicha Pasión: «Y será la meditación sin pena chica ni grande de la cabeza, y sin discurrir mucho por el pensamiento, sino como quien sencillamente mira al Señor en aquel paso, esperando lo que Él le quisiere dar» ${ }^{94}$. Pasada otra hora, se dedicará el sacerdote al estudio, a lo largo de otra hora, pasando después al descanso nocturno.

2. Al otro día, después de levantarse del sueño se rezará el breviario hasta la hora sexta inclusive, para después aparejarse a celebrar la eucaristía, pensando en Cristo conforme al paso que se meditó el día anterior. Una vez dicha la misa, se ha de recoger durante media hora para seguir gozando del Señor que se ha celebrado.

3. Después de este tiempo se dedicará toda la mañana a estudiar hasta la comida. Después de la comida recomienda la siesta, para después rezar el breviario hasta Completas.

4. Las tardes se han de gastar unos días en ir al campo, por el bien de la salud, otros en visitar enfermos, otros en conversar con quienes lo necesitan. "Y en esto me parece que debe emplear las tardes: en cosas que no sean oración o estudio, porque me parece que no podrá sufrir su cabeza tanto trabajo» ${ }^{95}$.

En la Carta 236, San Juan de Ávila pergeña otro programa de vida para uno de sus discípulos:

1. Comenzando la mañana el discípulo se ha de levantar e hincarse de rodillas en un lugar secreto y recogido, se signará y comenzará la confesión general con la mayor contrición posible. Posteriormente, estando tranquilo y en la postura que mejor le pareciere, pondrá en la imaginación a Nuestro Señor, de «una manera que traiga a reverencia y amor, para lo cual aprovechará dar una vuelta por la grandeza del mundo, mirando cómo aquel Señor, que está allí, gobierna las villas y la tierra; cómo rige los ángeles, hinche de gloria los santos; cómo, estando

94. Carta 225, lins. 60-63.

95. Carta 225, lins. 78-81. 


\section{Vocación y estados de perfección}

en los cielos por esencia, está también en los infiernos castigando a los dañados; cómo no hay cosa donde Él no está con su ser» ${ }^{96}$, y sigue describiendo con más detalles como debe realizar esa meditación sobre la grandeza y majestad de Jesucristo. Después de esa meditación volverá sobre sí mismo, pensando cuán indigno es de estar delante de ese Señor por tantas faltas y pecados cometidos. En ese momento meditará y reflexionará sobre como Dios es su creador y los grandes beneficios que le ha otorgado siempre. Esta meditación no requiere un tiempo concreto, sino «lo que el ánima gustare, porque el fin de esta oración no ha de ser pensar mucho, sino sacar fructo ${ }^{97}$. Posteriormente pasará a meditar la Pasión, teniendo orden según los días de la semana, aplicando un paso para cada día: «El lunes pensará cómo Cristo fue del huerto, con todo lo que pasó hasta que Pilato lo mandó azotar; el martes, pensar los azotes con todo lo que pasó hasta que lo quisieron coronar; el miércoles, pensar la coronación con todo lo demás, hasta que lo quisieron sacar con la cruz a cuestas; el jueves se ha de pensar hasta el punto que lo pusieron en la cruz y lo crucificaron; el viernes, todo lo demás hasta que expiró; el sábado glorioso lo bajaron de la cruz y lo sepultaron; el domingo, la resurrección $»^{98}$.

Esta meditación no es del todo rigurosa, pues si el alma tiene querencia de meditar alguna otra cosa puede realizarse. Respecto a tener una idea clara sobre la historia de la Pasión recomienda varias obras, como por ejemplo el passio duorum $^{99}$, de Fray Luis de Granada, «u otro que le parezca lo trata bien. Podrá tener esta orden, que el paso que hubiera de pensar lo haya bien leído, porque se le haga después fácil meditarlo» ${ }^{100}$. El modo de realizar la meditación será principalmente utilizando la composición de lugar. De esta meditación se han de seguir tres frutos: el primero es el conocimiento de lo mucho que debemos a Dios por el gran amor que nos tiene; el segundo es esperanza en la misericordia y redención; el tercero es caridad para con los prójimos. Al hilo de la meditación de la Pasión discurrirá las virtudes que se derivan de todos los pasos que ella contiene: «Podrá mirar la humildad y deseo de menosprecio que allí tuvo Cristo, para tener deseo de desechar las honras y amar el menosprecio, por verse semejante a tal Señor. Podrá mirar la paciencia grande que tuvo con sufrir, para animarse a padecer, y así ni más ni menos por las demás virtudes» ${ }^{101}$.

2. Después de esa hora de meditación, dando gracias a Dios por las gracias que le ha concedido, se celebrará la eucaristía. Los frutos de esa meditación se han de conservar durante todo el día, es decir, no hay que «derramar el cora-

96. Carta 236, lins. 15-21.

97. Carta 236, lins. 62-64.

98. Carta 236, lins. 77-84.

99. FRAY LUIS DE GRANADA, Libro de la oración y meditación (1554) c.3, 11: Obras, II, ed. Cuervo, 20-87, 257-274; Guía de pecadores, Lisboa 1556, 1, 3 p.2. ${ }^{a}$ c.4: Obras, X, 352-382.

100. Carta 236, lins. 105-108.

101. Carta 236, lins. 184-188. 


\section{Pedro Cayón Cagigas}

zón» en los negocios del mundo. Recomienda para este consejo la lectura del Tercer Abecedario de Francisco de Osuna: "Y si quiere tener alguna anchura en saber cómo se ha de hacer esto, lea en la Tercera parte del Abecedario de Fray Francisco de Osuna ${ }^{102}$ dos letras que allí pone que tratan de esto. La una es $M$, que dice: «Memoria ten de continuo y llama a Dios con suspiros». La otra es $R$, que dice: «Referir y sacar debes de toda cosa el amor» ${ }^{103}$.

3. Llegando a la noche se reservará hora y media de oración antes de cenar, «porque está el cuerpo más dispuesto», o, si no hay problema, una hora después de la cena. El modo será igual al de la mañana, es decir, tener a Dios presente, para pasar a realizar el examen de conciencia y pedir perdón por las faltas cometidas. Después de esto, reconciliado con Dios, pensará en «el estrecho paso de la muerte», haciendo como una especie de composición de lugar en la que se está mirándose a sí mismo muerto en una cama. De ahí ha de sacar doctrina y provecho para la voluntad, pensando en lo poco que vale el mundo y que bueno es en el momento del Juicio tener a Dios como amigo. Después se parará en los grandes deleites del paraíso, «si de aquel juicio sale para él». El fruto de estas consideraciones ha de procurarse que permanezca en la persona hasta acostarse.

Abreviando lo que aquí está, para que mejor la memoria lo retenga, he dicho que se aparten dos horas cada día para Dios, una a la mañana y otra a la noche. A la mañana se pensará un paso de la pasión, cada día el suyo, mientras la devoción no pidiere otro paso o misterio. Entrará el cuerpo en la oración con sosiego y pensando sin fuerza y poco a poco sacando misterios, teniendo a Dios presente, por una manera que atraiga a amor y esperanza. De la pasión se han de sacar tres puntos principales: amor de Dios y esperanza en Él y caridad con los prójimos, y luego las virtudes, mirando las que tuvo Cristo. En la muerte se ha de sacar: cuán poco nos ayudan allí nuestros amigos, ver la necesidad que tenemos de Dios, ver el pago que nos dará el mundo, que nuestro cuerpo será manjar de gusanos, y el estrecho juicio de Dios. Donde el ánima sintiere gustar de la oración, parará con el pensamiento ${ }^{104}$.

En los Escritos Menores aparece una carta dirigida a don Francisco de Guzmán. En ella, San Juan de Ávila destaca tres pautas que han de seguirse en la práctica del estado presbiteral:

1. No realizar pecados veniales, «porque de los mortales no hay que hablar a quien sigue al Señor» ${ }^{105}$. Habrá de guardarse de jurar, mentir y murmurar de defectos de prójimos, aunque sean pequeños.

102. FRANCISCO DE OsUnA, OFM, Tercera parte del libro llamado Abecedario espiritual, tr. 11, 16: N. B. AA. EE., t.16, Madrid 1911, 440-451. 492-513.

103. Carta 236, lins. 210-214.

104. Carta 236, lins. 455-468.

105. Siete nuevos escritos, Escrito $5^{\circ}$. 


\section{Vocación y estados de perfección}

2. Tendrá por regla dormir alrededor de siete horas diarias, de manera que siempre esté en pie y vestido a las cinco. Mientras se viste dar gracias al Señor por haberle guardado durante esa noche, y suplicarle que durante ese día le vista de adornos y virtudes, que a la esposa de Jesucristo convienen. Después de esto, se ha de postrar de rodillas, signarse y decir la confesión general. Debe considerar el atrevimiento que es ponerse en comunicación con Aquel a quien tanto debe, y por otra parte la misericordia y bondad con las que le recibe. Pasar a meditar un paso de la Pasión del Señor, gastando una hora en ello, hasta las seis. Luego leerá durante media hora un libro devoto. Pasará al estudio durante una hora y media, y luego se dispondrá a celebrar la eucaristía.

De esa hora hasta el momento del almuerzo el tiempo se ha de gastar en rezar de Prima a Nona, y emplearse en oración vocal, lección o estudio. Llegando a la comida, hará la bendición y terminará con el hacimiento de gracias. «Procure comer lo necesario, y no quede el estómago repleto, de manera que no quede hábil para leer o entender en otra tal cosa». Tanto después de comer como de cenar, por espacio de una hora, no ha de leer o rezar, sino tomar alguna recreación santa. Al cabo de ese tiempo, tomará una lección de gramática, rezará Vísperas y Completas, y pasará durante una hora en oración, y también debe rezar el Rosario. El tiempo que sobre se debe dedicar a obras de caridad, estudio, lección u oración vocal, conforme al tiempo disponible. Si realiza algo de recreación, que sea con personas santas y virtuosas. Por la noche, rezar Maitines y Laudes.

3. Recomienda el Maestro Ávila una dirección espiritual, «a la cual declare siempre todos los pensamientos que por su ánima pasaren; y al fin, no haga nada corporal ni espiritual sin su consejo».

Y confío en la bondad del Señor que haciendo esto, Él enseñará al alma sus divinos caminos, para que, desamparadas todas las pasiones y el mundo, con quietud sirva al Señor. El cual se lo conceda por su bondad inmensa, y enriquezca su ánima con tantos dones y virtudes, cuantas para servirle con menester.

Después de vistos estos programas de vida, podemos realizar una serie de conclusiones generales a modo de cinco preceptos ascéticos fundamentales, que compendian todo lo que San Juan de Ávila pide a los sacerdotes en sus prácticas diarias:

1. Dos momentos fuertes de oración diaria, tanto por la mañana como por la noche, han de dedicarse a la oración mental. Esta debe consistir unas veces en la Pasión de Cristo, otras en el paso de la propia muerte, el juicio de Dios o la amistad que tiene el Señor para con nosotros a pesar de nuestra indignidad. También en estos momentos se debe aprovechar para realizar el examen de conciencia diario.

2. Oración vocal diaria: rezo de todas las Horas canónicas y también recomienda el rezo del rosario. 


\section{Pedro Cayón Cagigas}

3. Eucaristía diaria. Dedicando para este momento una atención especial en dos apartados: en cuanto a meditación sobre el Señor y la concluyente acción de gracias.

4. Formación espiritual y teológica permanentes. Adquisición de libros de referencia especializados en estas materias.

5. Vida activa: consistente en el provecho de los prójimos, visita a enfermos, catequesis, etc.

Se ha esbozado aquí el camino ascético, con sus medios espirituales, intelectuales y pastorales, que debe seguir el presbítero según el Patrono del clero español. En definitiva, y sin ceñirnos a las circunstancias concretas que influían a aquellos presbíteros, vemos que para que todo sacerdote se halle a la altura de tal dignidad debe poseer amor a la formación intelectual continua, esmero en su vida espiritual y, al mismo tiempo, solicitud en su ejercicio del ministerio pastoral. Estas actitudes, que, por otra parte, están intrínsecamente unidas, si se intentan llevar a cabo eficazmente, dan la medida del ideal de perfección del sacerdocio ministerial que tenía en mente el Maestro Ávila.

\section{Estado episcopal}

Son muchos los escritos, y no sólo de carácter espiritual, donde el Maestro Ávila aborda el tema de la vida pastoral de los Obispos. Sería ingente la labor de sistematizar todo su pensamiento, por ello se expone como muestra un escrito espiritual en el que refleja claramente su preocupación por la reforma de este estado de vida cristiano.

En carta al Arzobispo don Pedro Guerrero pergeña el Maestro Ávila una especie de orientaciones de vida, que en rasgos generales consisten en una profunda conversión de corazón y frecuencia en el ejercicio de la oración. La «oración ha de ser el incensario con que el prelado amanse al Señor» ${ }^{106}$, para que aprenda a ser mendigo delante del Señor, importunándole mucho y encomendando al Señor el bien de su grey; que celebre la eucaristía diariamente si no hubiese impedimento; que se esfuerce en el ejercicio de predicar, el cual ha de ser muy continuo; que conozca las personas que se forman en los colegios, tanto rectores como colegiales; que cuide y escoja bien sus amistades para que no lleguen a ser dañosas; que no le tengan "en posesión de que no castiga», pues le menospreciarán; en palabras blando y dulce, y en obras duro y rígido, cuando sea menester (toma como referencia a San Gregorio ${ }^{107}$ ); que tenga vida austera y sencilla; también debe de hacerse de una persona discreta y fiel que examine las necesidades de los pobres, para que se les provea de lo necesario ${ }^{108}$.

106. Carta 177, líns. 53-54.

107. San Gregorio Magno, Moral. 1.20, c.3, 6: ML 76, 138.

108. Cf. Carta 177, líns. 45-101. 


\section{Vocación y estados de perfección}

\section{CONCLUSIÓN}

Después de realizado este estudio se puede comprobar fehacientemente que la figura del Maestro Ávila trata de ayudar a buscar la perfección o santidad en una línea de exigencia y fidelidad a los compromisos inherentes a la vocación cristiana. Esta postura de exigencia es fruto de una época de reforma que surge como respuesta ante un estilo de vida cristiana que había caído en la rutina e inercia negativa general. Hoy, la Iglesia, santa y pecadora, también tiene desgraciadamente en su seno costumbres que están muy en sintonía con la falta de honestidad vocacional de aquel convulso siglo XVI. Ante ello, el testimonio del Maestro Ávila sigue siendo totalmente válido y actual. La promoción de una formación seria que él defendió: tanto pastoral, como espiritual e intelectual, profunda y fiel a la Iglesia, sigue siendo necesaria; y la catequización y el testimonio de una vida cristiana por parte de los que formamos la Iglesia, laicos, religiosos y sacerdotes, ante un mundo cada vez más secularizado y falto de costumbres cristianas, también son inexcusables.

En nuestra época, todos estamos llamados a la constante renovación vocacional y a la continua conversión personal, y a descubrir y ofrecer cauces que promuevan el auténtico seguimiento de Cristo, en especial a aquellos que no encuentran un sentido veraz y perenne en sus vidas. En este sentido, el punto vista ascético, desde el que se ha enfocado este trabajo en los escritos avilistas, cobra un sano protagonismo; para ello podríamos aducir las palabras de Aurelio Fernández: «En la actualidad, una ascesis que ayude al hombre a dominar las fuertes inclinaciones al mal a las que está sometido, se hace cada día más perentoria, por cuanto los alicientes al consumismo representan en la actualidad una de las tentaciones más sutiles y graves a las que puede estar sometido el hombre y la mujer de nuestro tiempo» ${ }^{109}$. Los últimos Papas, sobre todo Pablo VI y Juan Pablo II, han hecho hincapié en la praxis moral de la ascética. Es este último, con motivo del primer centenario del Pontificio Colegio Español de Roma, dijo a los sacerdotes españoles allí presentes lo siguiente: «Todas las virtudes de la ascética cristiana deben ser en vosotros aquellas propias del pastor, asumiendo así un aspecto peculiar, que el Concilio Vaticano II define como 'ascética propia del pastor de ánimas' $(\mathrm{PO}, 13) \searrow^{110}$.

Por otra parte, y como ya se ha reflejado, la ascesis cristiana es tarea de la que ningún cristiano puede eximirse; es vocación para toda la Iglesia, teniendo en cuenta que debe explayarse con tipificaciones y configuraciones diferentes, acordes con la Iglesia de nuestro tiempo, y en correspondencia con la pluralidad de tipologías cristianas a las que se dirige e interpreta. Según afirma el espe-

109. A. FernándeZ, «Ascesis», en Diccionario de Teología Moral, 119.

110. Juan Pablo II, Homilía con motivo de la celebración del primer centenario del Pontificio Colegio Español de San José (Sábado, 28-III-1992). 
cialista K. C. Russel: «Así como la ascética es un programa de adiestramiento que condiciona los individuos hacia un fin espiritual, el tipo de ascética practicado en un periodo particular de la Iglesia depende de la comprensión propia del momento acerca de la naturaleza y efecto del pecado, como también de la visión de la santidad $\aleph^{111}$. Por todo ello, el espíritu de San Juan de Ávila, místico del siglo XVI, sigue siendo testimonio eficaz y actual en nuestro diario caminar en el siglo XXI.

Hoy la Iglesia universal se alegra del doctorado de San Juan de Ávila. Esperemos que este acontecimiento haga resonar todavía más la figura de aquel santo que con su vida participó en la ejemplar reforma católica del siglo XVI. Un santo que supo de una forma cabal adaptarse apostólicamente a los signos de los tiempos, con un espíritu que nunca se podrá obviar y que, por tanto, es totalmente válido también en nuestro tiempo.

111. K. C. Russel, «Ascetica», en M. DoWNEY, dir., Nuovo dizionario di spiritualità, 87. 